\title{
Mild traumatic brain injury: a risk factor for neurodegeneration
}

\author{
Brandon E Gavett ${ }^{1,2}$, Robert A Stern ${ }^{1,2}$, Robert C Cantu ${ }^{2,3,4}$, Christopher J Nowinski ${ }^{2,3}$ and Ann C McKee ${ }^{1,2,5,6 *}$
}

\begin{abstract}
Recently, it has become clear that head trauma can lead to a progressive neurodegeneration known as chronic traumatic encephalopathy. Although the medical literature also implicates head trauma as a risk factor for Alzheimer's disease, these findings are predominantly based on clinical diagnostic criteria that lack specificity. The dementia that follows head injuries or repetitive mild trauma may be caused by chronic traumatic encephalopathy, alone or in conjunction with other neurodegenerations (for example, Alzheimer's disease). Prospective longitudinal studies of head-injured individuals, with neuropathological verification, will not only improve understanding of head trauma as a risk factor for dementia but will also enhance treatment and prevention of a variety of neurodegenerative diseases.
\end{abstract}

A complex interaction between genetic and environmental risk factors has often been a suspected trigger for the development of neurodegenerative disease. Yet of all the possible environmental risk factors put forth, trauma to the central nervous system is one of the most consistent candidates for initiating the molecular cascades that result in Alzheimer's disease (AD), Parkinson's disease (PD), and amyotrophic lateral sclerosis [1-3]. Recent evidence also suggests that mild traumatic brain injury (TBI), including repetitive concussive and subconcussive trauma, can provoke another distinctive neurodegeneration: chronic traumatic encephalopathy (CTE) [4].

CTE has to date only been described neuropathologically in individuals with a history of repetitive closed head injury, most often occurring in the context of contact sports. It remains to be determined whether

*Correspondence: amckee@bu.edu; Ann.Mckee@va.gov

${ }^{5}$ Geriatric Research Education Clinical Center, Edith Nourse Rogers Memorial VA

Hospital, 200 Springs Road, Bedford, MA 01730, USA

Full list of author information is available at the end of the article there is a genetic susceptibility to the development of CTE and whether a single severe traumatic head injury may also be causative.

\section{Chronic traumatic encephalopathy}

CTE is a progressive tauopathy with a distinct clinical and neuropathological profile that becomes symptomatic many years after an individual experiences repeated concussive or subconcussive blows to the head. The characteristic features of CTE include: extensive tau immunoreactive neurofibrillary tangles and astrocytic tangles throughout the frontal and temporal cortices in a patchy, superficial distribution, with focal epicenters at the depths of sulci and around small vessels; extensive tau neurofibrillary tangles in the limbic and paralimbic regions, diencephalon, basal ganglia and brainstem; and a relative paucity of $\beta$-amyloid (A $\beta$ ) deposits, although diffuse plaques are present in roughly one-half of the cases. In advanced disease, there are also macroscopic abnormalities: generalized cerebral atrophy and enlarged ventricles; atrophy of the medial temporal lobe structures and mammillary bodies; cavum septi pellucidi, often with fenestrations; and pallor of the substantia nigra.

CTE typically becomes symptomatic in mid-life as disordered cognition, most pronounced in the areas of memory and executive functioning; disturbances in mood and comportment (for example, apathy, irritability); and Parkinsonian signs [4]. CTE was in the past referred to as dementia pugilistica, which reflected the prevailing notion that this condition was restricted to boxers athletes who engaged in a sport with purposeful repeated blows to the head. Recent research, however, has demonstrated neuropathological evidence of CTE in retired American football players, a professional wrestler, a professional hockey player and a soccer player [4], as well as in nonathletes [5]. It is probable that many individuals are susceptible to CTE, including those who experience falls, motor vehicle accidents, assaults, epileptic seizures, or military combat, and that repeated mild closed head trauma of diverse origin is capable of instigating the neurodegenerative cascade leading to CTE.

Although neuropathologically distinct, the clinical presentation of CTE may be very similar to $A D$ or 
frontotemporal lobar degeneration, especially in advanced disease [4]. Individuals may meet clinical criteria for $\mathrm{AD}$ or frontotemporal lobar degeneration, even though the age of onset for CTE is generally younger than that for $\mathrm{AD}$ and the course of the disease is typically slower than that of $\mathrm{AD}$ or frontotemporal lobar degeneration. These similarities bring into question the specificity of the clinical diagnostic criteria for AD used in the multitude of case-control studies that have established TBI as a risk factor for AD. Without neuropathological verification, the prevalence of CTE neuropathology in a demented sample is unknown.

\section{The link between head trauma, Alzheimer's disease and other neurodegenerations}

Multiple epidemiological studies have shown that mild TBI is a risk factor for late-life dementia, especially AD [1]. Although the evidence is not without its detractors (for example [6]), meta-analytic studies support the notion that AD risk is increased after TBI, at least for men [7]. In almost all of the studies investigating TBI and $\mathrm{AD}$ risk, $\mathrm{AD}$ was diagnosed based on clinical criteria for probable or possible $\mathrm{AD}$, without neuropathological verification. Only one study has evaluated the risk of $A D$ following TBI using standardized neuropathological criteria for AD [8] - finding that a history of TBI was a risk factor for $A D$, particularly in individuals without the apolipoprotein e4 allele. As the majority of reports were based on clinical diagnostic criteria that may lack the specificity to rule out other causes of dementia [9], it is possible that the increased incidence of dementia following head injuries is due to CTE, alone or in conjunction with other neurodegenerative conditions such as AD.

Multiple studies have also indicated that a history of trauma to the central nervous system is a risk factor for other neurodegenerative conditions, including PD $[2,10]$ and amyotrophic lateral sclerosis $[3,11,12]$. Widespread TAR DNA-binding protein 43 (TDP-43)-positive inclusions have been reported in the neocortex in cases of CTE [13]. We recently also found TDP-43 immunoreactive inclusions and neurites in the frontal and temporal cortices, medial temporal lobe, basal ganglia, diencephalon, and brainstem in 10 out of 12 cases of CTE. Three of these athletes with CTE also had a progressive motor neuron disease characterized by profound weakness, atrophy, spasticity, and fasciculations, and abundant TDP-43-positive inclusions were found in the spinal cord, as well as tau neurofibrillary changes, upon postmortem examination [14].

These findings support epidemiologic evidence that the repetitive head trauma experienced in sports might also be associated with the development of a motor neuron disease $[3,11,14]$. TBI could conceivably trigger multiple molecular pathways that result in the overproduction and aggregation of a number of key proteins that form pathological aggregates in neurodegenerative diseases. TBI may not only provoke the accumulation of hyperphosphorylated tau protein, as CTE, but also of $\mathrm{A} \beta$, $\alpha-$ synuclein, and TDP-43, possibly increasing the likelihood of developing $\mathrm{AD}, \mathrm{PD}$, and motor neuron disease. Experimental evidence indicates that $\mathrm{A} \beta$ neurotoxicity is enhanced in the presence of tau [15]. It is conceivable that tau deposition provoked by repetitive head trauma accelerates $A \beta$ toxicity in individuals with age-related $A \beta$ plaques [16], triggering the more rapid onset of $\mathrm{AD}$. Furthermore, aggregates of $\alpha$-synuclein and $A \beta$ have been described after experimental TBI in animals and after acute brain trauma in humans [17].

\section{The need for future chronic traumatic encephalopathy research}

There is clearly a need for improved accuracy of clinical diagnostic criteria in the differential diagnosis of CTE and $\mathrm{AD}$, which will require new prospective longitudinal studies terminating in autopsy. Equally important is the need for standardized criteria to diagnose CTE neuropathologically, either alone or as mixed disease.

Although the evidence suggests that central nervous system trauma is a risk factor for CTE, as well as for AD, $\mathrm{PD}$, and motor neuron disease, very little is known about what type, frequency, or amount of trauma is necessary to induce the accumulation of these pathological proteins. Future prospective studies will be necessary to answer these questions as well as to determine at what age the nervous system is most susceptible to the deleterious effects of trauma and whether proper management of acute head injuries is effective in reducing the incidence of late-life neurodegenerative dementias.

Accurate differential diagnosis in the preclinical or early phases of CTE and AD may have important therapeutic implications as well. For example, therapeutics selectively targeting $A \beta$ will be misguided if the predominant neuropathological abnormality is hyperphosphorylated tau protein, as in CTE. Furthermore, use of experimental models of head injury to provoke neurodegeneration in genetically modified animals may ultimately serve to identify key components of the pathogenetic molecular cascades as well as susceptibility genes for a variety of neurodegenerative diseases.

\section{Abbreviations}

$A \beta$, $\beta$-amyloid; $A D$, Alzheimer's disease; $C T E$, chronic traumatic encephalopathy; PD, Parkinson's disease; TBI, traumatic brain injury; TDP-43, TAR DNA-binding protein 43.

\section{Competing interests}

RAS has been a paid consultant for Elan Pharmaceuticals and Outcome Science. He also receives royalties from Psychological Assessment Resources, Inc., as a co-developer of the Neuropsychological Assessment Battery. The other authors declare they have no competing interests. 


\section{Acknowledgements}

The present work was supported by NIA P30AG13846 (supplement

0572063345-5), the National Operating Committee on Standards for Athletic

Equipment and the Department of Veterans Affairs. This work was also

supported by an unrestricted gift from the National Football League. The

funding sources were not involved in the preparation, review, or approval of

this manuscript.

\section{Author details}

'Department of Neurology, Boston University School of Medicine, 72 East Concord St., B-7800, Boston, MA 02118, USA. ${ }^{2}$ Center for the Study of Traumatic Encephalopathy, Boston University, 72 East Concord St., B-7800, Boston, MA 02118, USA. ${ }^{3}$ Sports Legacy Institute, 230 3rd Ave., Waltham, MA 02451, USA. ${ }^{4}$ Department of Neurosurgery, Emerson Hospital, 131 ORNAC Suite 820, John Cuming Building, Concord, MA, 01742, USA. ${ }^{5}$ Geriatric Research Education Clinical Center, Edith Nourse Rogers Memorial VA Hospital, 200 Springs Road, Bedford, MA 01730, USA. ${ }^{6}$ Department of Pathology and Laboratory Medicine, Boston University School of Medicine, 670 Albany Street - 4th Floor, Boston, MA 02118, USA.

\section{Published: 25 June 2010}

\section{References}

1. Mortimer JA, van Duijn CM, Chandra V, Fratiglioni L, Graves AB, Heyman A, Jorm AF, Kokmen E, Kondo K, Rocca WA: Head trauma as a risk factor for Alzheimer's disease: a collaborative re-analysis of case-control studies. EURODEM Risk Factors Research Group. Int J Epidemiol 1991, 20:S28-S35.

2. Goldman SM, Tanner CM, Oakes D, Bhudhikanok GS, Gupta A, Langston JW: Head injury and Parkinson's disease risk in twins. Ann Neurol 2006, 60:65-72.

3. Chen H, Richard M, Sandler DP, Umbach DM, Kamel F: Head injury and amyotrophic lateral sclerosis. Am J Epidemiol 2007, 166:810-816.

4. McKee AC, Cantu RC, Nowinski CJ, Hedley-Whyte ET, Gavett BE, Budson AE, Santini VE, Lee HS, Kubilus CA, Stern RA: Chronic traumatic encephalopathy in athletes: progressive tauopathy after repetitive head injury. J Neuropathol Exp Neurol 2009, 68:709-735.

5. Roberts GW, Whitwell HL, Acland PR, Bruton CJ: Dementia in a punch-drunk wife. Lancet 1990, 335:918-919.

6. Fratiglioni L, Ahlbom A, Viitanen M, Winblad B: Risk factors for late-onset Alzheimer's disease: a population-based, case-control study. Ann Neurol 1993, 33:258-266.

7. Fleminger S: Head injury as a risk factor for Alzheimer's disease: the evidence 10 years on; a partial replication. J Neurol Neurosurg Psychiatr 2003,
74:857-862.

8. Jellinger KA, Paulus W, Wrocklage C, Litvan I: Traumatic brain injury as a risk factor for Alzheimer disease. Comparison of two retrospective autopsy cohorts with evaluation of ApoE genotype. BMC Neurol 2001, 1:3-6.

9. Kukull WA, Larson EB, Reifler BV, Lampe TH, Yerby MS, Hughes JP: The validity of 3 clinical diagnostic criteria for Alzheimer's disease. Neurology 1990, 40:1364-1369

10. Ben-Shlomo Y: The epidemiology of Parkinson's disease. Baillieres Clin Neurol 1997, 6:55-68.

11. Schmidt S, Kwee LC, Allen KD, Oddone EZ: Association of ALS with head injury, cigarette smoking and APOE genotypes. J Neurol Sci 2010, 291:22-29.

12. Chen H, Richard M, Sandler DP, Umbach DM, Kamel F: Head injury and amyotrophic lateral sclerosis. Am J Epidemiol 2007, 166:810-816.

13. King A, Sweeney F, Bodi I, Troakes C, Maekawa S, Al-Sarraj S: Abnormal TDP-43 expression is identified in the neocortex in cases of dementia pugilistica, but is mainly confined to the limbic system when identified in high and moderate stages of Alzheimer's disease. Neuropathology 2010. [Epub ahead of print]

14. McKee AC, Gavett BE, Stern RA, Nowinski CJ, Cantu RC, Kowall NW, Perl DP, Hedley-Whyte ET, Price B, Sullivan C, Morin P, Lee H, Kubilus CA, Danshevar DH, Wulff M, Budson AE: TDP-43 proteinopathy and motor neuron disease in chronic traumatic encephalopathy. J Neuropathol Exp Neurol 2010 [manuscript accepted for publication].

15. Roberson ED, Scearce-Levie K, Palop JJ, Yan F, Cheng IH, Wu T, Gerstein H, Yu $G Q$, Mucke L: Reducing endogenous tau ameliorates amyloid betainduced deficits in an Alzheimer's disease mouse model. Science 2007, 316:750-754.

16. Mann DM, Brown AM, Prinja D, Jones D, Davies CA: A morphological analysis of senile plaques in the brains of non-demented persons of different ages using silver, immunocytochemical and lectin histochemical staining techniques. Neuropathol App/ Neurobio/ 1990, 16:17-25.

17. Uryu K, Chen XH, Martinez D, Browne KD, Johnson VE, Graham DI, Lee VM, Trojanowski JQ, Smith DH: Multiple proteins implicated in neurodegenerative diseases accumulate in axons after brain trauma in humans. Exp Neurol 2007, 208:185-192.

doi:10.1186/alzrt42

Cite this article as: Gavett BE, et al: Mild traumatic brain injury: a risk factor for neurodegeneration. Alzheimer's Research \& Therapy 2010, 2:18. 